into mud, which stained our whiten ashed walls a reddish brown. I see that it fell in Sicily on March 29 and $30 . .$. It is quite a different colour from the dust the sirocco occasionally brings us.

\section{Monkeys in the West Indies}

YOU have recently had communications in NATURE (vol. $x x i$. p. I3I and 371) from two gentlemen residing in the Istand of Dominica, in the West Indies, Messrs. Edmund Watt and John Imray, on the incorrectness of Prof. Mivart's statement, in his paper on "Tails," regarding the non-existence of monkeys in these islands.

These gentlemen are quite as much in error as Prof. Mivart in asserting that the only islands where monkeys are to be found are St. Christopher and Nevis, and Mr. Imray especially, who says, "It certainly appears remarkable that no species of monkey should exist in the wild state in any of these islands along the whole range from Grenada to Jamaica," with the exception of the two already named.

Not only are there monkeys in the Island of Grenada, but they exist in large numbers, and enjoy all the wildness that the deep forests of the mountains secure to them.

Riding across the country over the mountain ridges, these animals are frequently to be seen skipping amongst the branches of the surrounding trees, and they have often been shot by sportsmen who have ventured into the " high wcods."

Exciting rencontres have been met with by those who have gone in pursuit of the monkeys. When one is shot at it sets up a "houp, houp," that, like the whistle of Roderick Dhu,-

$$
\begin{aligned}
& \text { ". . . garrisons the glen, } \\
& \text { A subterraneous host to heaven," given," }
\end{aligned}
$$

and from all sides you are pelted with nuts and seeds and boughs gathered from the trees by the offended tribe. Should you succeed in maiming or killing one of them, the strrvivors assume so threatening an attitude that, being as a rule singlehanded, you are quite content to retire from the scene of the contest, consoling yourself with the reflection that discretion is the better part of valour.

It is even difficult to secure the skin of one of these animals, for if there are numbers present, when one is shot the others bear away their injured brother beyond your reach.

It can therefore be readily understood how difficult it is to obtain one alive. Not long ago, however, I thought I had secured a prize. One of these "natives" was bronght into the town for sale. He was such a handsome fellow, and looked so interesting, that I determined to purchase him. What I was particularly struck with was his being so tame, as he allowed me, without moving a muscle, to place my hand upon his head and about his face. Having been called away for an instant, I missed my opportunity, as he was taken by another gentleman who had come up in my absence. That same evening I saw him again, and on a closer examination I discovered the cause of his docility. He was blind! That was the reason he had been caught so easily.

It is not at all to be wondered at that neither Rochefort, Du Tertse, nor La Bat, the three earliest writers on these islands quoted by Mr. Imray, mention the existence of monkeys in Grenada. They had no opportunities of knowing it. La Bat alone travelled about the island a little, but this was only on our western coast, and the Caribs, who might have informed them on this subject and on many others, had been most carefully exterminated by their countrymen.

D. G. G.

Grenada, A pril 27

IN a letter that sppeared in NATURE, vol, xxi. p. $37 \mathrm{I}$, on "Monkeys in the West Indies," I observed that it seemed remarkable "that no species of monkey should exist in the wild state in any of the West India Islands along the whole range from Grenada to Jamaica," \&c. Since writing the above I have discovered that monkeys are abundant in Grenada in the wild state, and that they are very destructive to the growing crops. Mr. Watt (now at Cape Coast Castle), who took exception to Prof. Mivart's statement in regard to the existence of monkeys in the West Indies, called my attention also to this fact.

Have these Grenada apes been introduced, or are they indigenous? is the question, if indeed it be a question. The historic evidence points, I think, conclusively to their introduction, though I have not been able to ascertain the when and the how, as in the case of St. Kitts. The two old French authors quoted in my former letter-Rochefort, 1665 , and Du Tertse, 1667 enumerate the mammalia at that time existing in the Antilles as known to them, and $\mathrm{Dr}$ Tertse was well acquainted with Grenada; but no species of ape is amongst the number.

A letter from Mr. Sclater in NATURE, vol. xx. p. I 53, proved that the St. Kitts Monkeys were referable to the green monkey (Cercopithecus callitrichus, Geoffr.) of Western Africa. Can Mr. Sclater or any of your readers give similar information regarding the species of the Grenada ape?

I have been informed that apes are also to be found wild in Montserrat.

Sir Robert Schomburgk, in his "History of Barbados," says, with reference to the Quadrumana : "The most interesting [of the mammalia] is the Barbados monkey, now nearly extinct, although formerly so frequent that the Legislature set a price upon its head. I have much to regret, on account of natural history, that my endeavours to procure a specimen for the purpose of determining the species have entirely failed. From the outer appearance of a living specimen I consider it to be Cepus [Cebus?] capucinus, Geoffr., the Say, or Weeper, or a very closely-allied species. It is not likely that it was introduced, as the first settlers found it in large numbers on their arrival."

Prof. St. George Mivart, who stands in the foremost rank as an authority on all such matters, in an article on "The Geo. graphy of Living Creatures," in the Contemporary Review for February last, makes the following remarks:- "The West Indian Islands, again, are admirably suited for such creatures as apes, yet none are indigenous to that region, though they rapidly increase when they have been introduced." He says in a note: "Trinidad is really a detached part of the continent of South America."

As all the historic facts go to prove that no species of the Quadrumana existed in the Lesser Antilles when first settled, it certainly does appear much more probable that the apes stated to have been found in Barbados by the first settlers had been introduced from Trinidad or the South American continent than that they existed as native to the island.

Dominica, April 24

\section{The Recent Volcanic Eruption in Dominica}

I AM indebted to Mr. Thomas Raine, of the Colonial Bank, Barbados, for the following analysis of the volcanic dust which fell in Roseau-the capital of that island-and the surrounding country during the eruption from the crater of the "Boiling Lake" on January II in the present year. The analysis was made in the Analytical Laboratory, Barbados, on January 19, by Mr. George Hughes, formerly senior assistant to Dr. A. Voelker, F.R.S., the sample of volcanic dust having been collected during the eruption and forwarded immediately afterwards to Barbados. Mr. Hughes thinks that the dust "has not been exposed directly to the action of fire to any extent, or the percentage of oxide of iron would have been higher and the pyrites less-oxide of iron being one of the products from the combustion of pyrites."

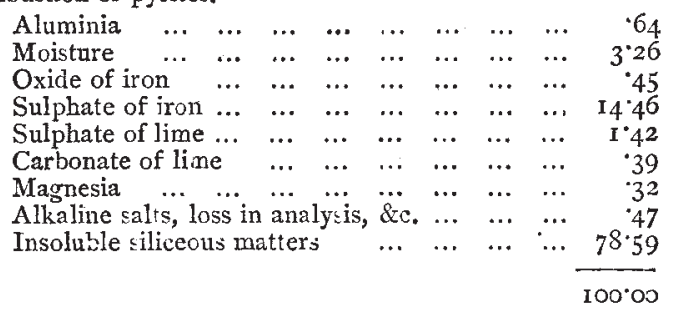

EDMUND WATT

Government House, Cape Coast, West Africa, April 23

\section{Cup Stones, Cup-Marked Stones, or Cups and Rings}

THE interesting paper on "A Scottish Crannog" in NATURE, vol. xxii. p. 13 , is illustrated on p. 16 by an engraving (Fig. 3) which exactly represents the "Cups and Rings" that have long excited the curiosity of anthropologists on Rombald's Moor, near Ilkley, West Yorkshire. These markings, which I have examined within the past week, are on detached flattish rocks of millstone grit, immediately to the south-west of the village of Ilkley, and near to what are known as the Panorama Rocks. 